\title{
Decreased SATB1 expression promotes AML cell proliferation through NF-KB activation
}

\author{
Xiaodan Luo* ${ }^{*}$, Lihua Xu, Xiaohong Wu, Huo Tan and Lian Liu
}

\begin{abstract}
Background: Special AT-rich sequence-binding protein 1 (SATB1) is a chromatin-remodeling protein that regulates gene expressions in different types of cancer. Up-regulation of SATB1 is linked with progression of tumors. Our previous study showed that SATB1 expression was decreased in T cell leukemia/lymphoma. The contrary roles of SATB1 in solid organ tumors and hematology malignancy may provide hints to study the function of SATB1.

Methods: To characterize SATB1 mRNA and protein expression in acute myeloid leukemia (AML), we performed qRTPCR and Western blot on bone marrow mononuclear cells from 52 newly diagnosed AML patients. Stable HL-60 cell lines with knockdown of SATB1 by shRNAs sequences (HL-60 SATB1-shRNA1 and HL-60 SATB1-shRNA2) were established. Cell proliferation, cell cycle and cell invasiveness were analyzed. Murine model was established using HL-60 SATB1-shRNAs treated nude mice and tumorigenicity was compared to study the role of SATB1 in vivo. Global gene expression profiles were analyzed in HL-60 cells with SATB1 knockdown to investigate the mechanisms underlying the regulation of AML cell growth by SATB1.

Results: We found that SATB1 expression was significantly decreased in patients with AML compared to normal control, and was increased after complete remission of AML. Knockdown of SATB1 enhanced the proliferation of HL-60 cells and accelerated S phase entry in vitro, and promoted the tumor growth in vivo. Global gene expression profiles were analyzed in HL-60 cells with SATB1 knockdown and the differentially expressed genes were involved in NF-KB, MAPK and PI3 K/Akt signaling pathways. Nuclear NF-KB p65 levels were significantly increased in SATB1 depleted HL-60 cells.
\end{abstract}

Conclusions: Decreased SATB1 expression promotes AML cell proliferation through NF-KB activation. SATB1 could be a predictor for better response to treatment in AML.

Keywords: SATB1, Acute myeloid leukemia, Gene expression profiling, RNA interference, NF-KB

\section{Background}

Acute myeloid leukemia (AML) is a clinically and genetically heterogeneous disease that is fatal for over $80 \%$ of patients, particularly for those older than 60 years of age, who have less than $5 \%$ to $10 \% 5$-year survival [1-3]. Unlike the booming development of therapies for lymphoid malignancies, myeloid drug development lagged behind due to less progress in understanding the genetic basis and pathophysiology of AML. For years, recurrent genetic abnormalities or some genetic mutations were

*Correspondence: xdluo@gzhmu.edu.cn

Department of Hematology, First Affiliated Hospital, Guangzhou Medical University, Guangzhou 510230, China found to clearly interact to drive the initiation, progression and relapse of AML. For example, AML with mutations of FLT3-ITD, c-Kit, TP53, etc. often has poor response to chemotherapy, high relapse rate and aggressive progression [2-8]. Chemotherapy for AML remained largely unchanged for decades, clinical response of targeted therapy is limited and the survival improvements over time were attributable mostly to hematopoietic stem cell transplantation (HSCT) $[2,5,9]$. New chromosomal aberrations, epigenetic changes and mutations of AML continue to be reported, and risk stratification is now based on genetic, genomic, and molecular characteristics which help determine the effect on prognosis, as well as provide new insights into the mechanisms of AML. 
Special AT-rich sequence-binding protein 1(SATB1) is a chromatin-remodeling protein that has been shown to play an important role in tumor progression and metastasis. Aberrant expression of SATB1 was reported in various types of cancers, including laryngeal squamous cell carcinoma, gastric cancer and breast cancer $[10,11]$. High SATB1 expression is usually correlated with high metastatic potential and poor prognosis of cancer [1217]. Contrary to observations in solid tumors, SATB1 appears to suppress the progression of leukemia and lymphoma. SATB1 deficiency causes severe immunodeficiency and multiple defects in T-lineage development [18-23]. We previously reported that SATB1 expressions were decreased in T cell leukemia/lymphoma (T-ALL), Knockdown of SATB1 significantly enhanced invasiveness of Jurkat cell in vitro [24]. It is reported that SATB1 binding to the enhancer of Sfpi1 resulted in reduced PU.1 expression in myeloid progenitor cells, which indicated that SATB1 dysfunction is associated with a subset of human AML patients [25]. However, less is known about the association between SATB1 and AML, whether SATB1 is implicated in the development of AML warrants further exploration.
In this study, we investigated the role of SATB1 in AML. We determined differences in SATB1 expression of initial AML and the control samples, paired initial and complete remission (CR) samples to find whether SATB1 played a role in the development of AML. We found that SATB1 expression was decreased in AML patients and increased after these patients received CR. We further studied the roles of SATB1 on AML in vitro and in vivo by shRNAs mediated knockdown of SATB1. We showed that knockdown of $S A T B 1$ enhanced the proliferation of AML cells and accelerated $S$ phase entry in vitro and promote tumorigenicity in vivo. We then analyzed the global gene expression profiles to investigate the mechanisms underlying the regulation of AML cell growth by SATB1 (part of the results were published as abstract in the 59th ASH annual Meeting: Blood 2017 130:1238).

\section{Methods}

Patients and clinical characteristics

Seventy-three AML patients from Oct 2015 to Jun 2017 and 38 healthy donors as control were enrolled in this study. Characteristics of newly diagnosed patients are described in Table 1. Peripheral blood samples from

Table 1 Patient Characteristics

\begin{tabular}{|c|c|c|c|c|c|}
\hline \multirow[t]{2}{*}{ Variable } & \multicolumn{2}{|l|}{ SATB $1_{\text {low }}(\mathrm{N}=32)$} & \multicolumn{2}{|c|}{$S A T B 1_{\text {high }}(N=20)$} & \multirow[t]{2}{*}{$P$ value } \\
\hline & Median (range) & No. & Median (range) & No. & \\
\hline Age, years & 50.5 (19-78) & & $51(16-79)$ & & 0.839 \\
\hline$\leq 55$ & & 19 & & 12 & \\
\hline$>55$ & & 13 & & 8 & \\
\hline Gender & & & & & 0.430 \\
\hline Male & & 18 & & 9 & \\
\hline Female & & 14 & & 11 & \\
\hline WBC $\left(\times 10^{9}\right)$ & $16.82(0.7-198.34)$ & & $11.32(0.6-283.8)$ & & 0.549 \\
\hline $\mathrm{RBC}\left(\times 10^{12}\right)$ & $2.4(1.33-4.49)$ & & $2.715(1.25-4.04)$ & & 0.706 \\
\hline $\mathrm{HGB}(\mathrm{g} / \mathrm{L})$ & $72(49-120)$ & & $83.5(40-129)$ & & 0.600 \\
\hline $\operatorname{PLT}\left(\times 10^{9}\right)$ & $47(3-97)$ & & $56(8-104)$ & & 0.624 \\
\hline Blast (\%) & $60(19.7-100)$ & & 71.25 (22-94) & & 0.420 \\
\hline \multicolumn{6}{|l|}{ FAB subtype } \\
\hline MO & & 1 & & 0 & \\
\hline M1 & & 2 & & 3 & \\
\hline M2 & & 9 & & 6 & \\
\hline M3 & & 6 & & 3 & \\
\hline M4 & & 5 & & 3 & \\
\hline M4Eo & & 1 & & 0 & \\
\hline M5 & & 6 & & 4 & \\
\hline Mixed AML & & 2 & & 1 & \\
\hline CR rate & & $57.14 \%$ & & $76.47 \%$ & 0.189 \\
\hline Missing value ${ }^{a}$ & & 4 & & 3 & \\
\hline
\end{tabular}

WBC, white blood cell; RBC, red blood cell; $H G B$, hemoglobin; $P L T$, platelet; $C R$, complete remission

${ }^{\text {a }}$ Four patients refused the treatment after diagnosed and three patients died during the first cycle of chemotherapy 
AML patients were obtained at initial diagnosis $(\mathrm{N}=52)$ with informed consent from patients or their legal guardians. All initial samples were obtained before any antileukemia treatment was given. The study was approved by the Committee on the Ethics of the First Affiliated Hospital of Guangzhou Medical University (Permit number: 2012-41).

\section{Mice}

$\mathrm{BALB} / \mathrm{c}(\mathrm{H}-2 \mathrm{~d}, \mathrm{n}=12)$ nude mice were purchased from Animal experimental center, Guangdong, China. Nude mice were housed and maintained in a specific pathogen-free environment and used when they were between 4 and 5 weeks of age. The protocol was approved by the Committee on the Ethics of Animal experimental center, Guangdong, China (Permit number: SYXK 2016-0168). HL-60 SATB1-shRNA1 and HL-60 control cells $\left(1 \times 10^{7}\right)$ were injected subcutaneously in SATB1-shRNA1 and control mice, respectively. Tumor size was measured everyday and tumor volume was calculated by the formula: tumor volume $\left[\mathrm{mm}^{3}\right]=($ length $[\mathrm{mm}]) \times($ width $[\mathrm{mm}])^{2} \times 0.5[26]$.

\section{Cell lines}

HL-60, HEL, THP-1 cells (Cell Bank, Chinese Academy of Sciences) and NB4 cells (Cell Resource Center, IBMS, CAMS/PUMC) were cultured in RPMI-1640 medium supplemented with $10 \%$ fetal bovine serum (FBS; Hyclone, Logan, UT), penicillin (100 units $/ \mathrm{ml}$ ), and streptomycin (100 units/ml) maintained at $37{ }^{\circ} \mathrm{C}$ in humidified $5 \% \mathrm{CO}_{2}$ incubator.

\section{Plasmid Construction and Retroviral Infection}

After synthesis of the oligoduplexes, the GV248.puro plasmid vector was digested with AgeI and EcoRI restriction endonucleases. Next, the SATB1-specific shRNAs were cloned into the GV248.puro vector. The successful plasmid construction was verified by DNA sequencing. Production of lentivirus was performed according to the instructions; HL-60 cells were subjected with infection of lentivirus expressing SATB1-shRNA1 and SATB1shRNA2 or GV248 (empty vector). HL-60 SATB1-shRNA and HL-60-CTR cells were cultured with puromycin for 3 days to produce stable $S A T B 1$ knockdown cell line. Targeted SATB1 sequence is as follows: SATB1-shRNA1, GGATTTGGAAGAGAGTGTC; and SATB1-shRNA2, GTCCACCTTGTCTTCTCTC.

\section{RNA extraction and quantitative real-time PCR assays (qRT-PCR)}

Total RNA was extracted using TRIzol reagent (Invitrogen). Complementary DNA (cDNA) was synthesized from $1 \mu \mathrm{g}$ of total RNA according to RevertAid ${ }^{\mathrm{TM}}$
First-Strand cDNA Synthesis Kit \#K1622 instruction (Thermo Scientific). cDNAs were subjected to qRT-PCR analysis with specific primers. qRT-PCR was performed using a FQD-48A (M2) instrument (BIOER, China) with iQTM SYBR Green supermix (Bio-Rad). All reactions were run in triplicate in three independent experiments and amplified in a $10 \mu \mathrm{l}$ reaction according to the manufacturer's protocol. Cycling conditions included an initial hold step $\left(95^{\circ} \mathrm{C}\right.$ for $\left.30 \mathrm{~s}\right)$ and 40 cycles of a twostep PCR $\left(95^{\circ} \mathrm{C}\right.$ for $30 \mathrm{~s}$ and then $53^{\circ} \mathrm{C}$ for $\left.30 \mathrm{~s}\right)$, followed by a dissociation step $\left(95^{\circ} \mathrm{C}\right.$ for $15 \mathrm{~s}, 60^{\circ} \mathrm{C}$ for $30 \mathrm{~s}$, and then a sequential increase to $95{ }^{\circ} \mathrm{C}$ ). Relative messenger RNA (mRNA) expression was calculated by the comparative $2^{-\triangle \Delta C T}$ method [27]. The primers were: SATB1 (Forward: 5'-TGCAAAGGTTGCAGCAACCAAAAGC -3'; Reverse: 5'-AACATGGATAATGTGGGGCGGCCT $-3^{\prime}$ ), GAPDH (Forward: 5' - TGTTG CCATCAATGACC CCTT-3'; Reverse: 5'-CTCCACGACGTAC TCAGCG $\left.-3^{\prime}\right)$; GAPDH was used as an internal control.

\section{Cell Proliferation assay}

HL-60 SATB1-shRNA1 cells, HL-60 SATB1-shRNA2 cells and HL-60 CTR cells were planted at a density of 2000 cells/well in 96-well plates and maintained at $37{ }^{\circ} \mathrm{C}$ in humidified 5\% CO2 incubator for $24 \mathrm{~h} .10 \mu \mathrm{l}$ of the Cell Counting Kit-8 (CCK8, Dojindo, Japan) solution was added per well and the plate was incubated for $4 \mathrm{~h}$, the absorbance at $450 \mathrm{~nm}$ was measured on a microplate reader.

\section{Cell invasion assay}

The invasive potential of HL-60 SATB1-shRNA1 cells, HL-60 SATB1-shRNA2 cells was examined using transwell inserts fitted with polycarbonate filters $(8-\mu \mathrm{m}$ pore size, Costar, Cambridge, MA) coated with matrigel (BD Biosciences, Bedford, MA). Matrix solutions within transwells were polymerized at $37^{\circ} \mathrm{C}$ for $1 \mathrm{~h}$ and dried onto the transwells overnight at room temperature. Cells were seeded in the upper compartment without FBS medium while lower wells contained 10\% FBS medium. After $48 \mathrm{~h}$ of incubation, the cells in the upper chamber were removed while other cells, which had passed through the filter, were fixed with $3.7 \%$ paraformaldehyde, stained with $0.2 \%$ crystal violet, counted, and captured at $\times 100$ and $\times 400$ magnifications using the camera on inverted microscope. Contents of the lower compartments were collected, and migrated cells were also counted.

\section{Cell Cycle Analysis}

Cell cycle distribution of HL-60 SATB1-shRNA1 cells, HL-60 SATB1-shRNA2 cells and HL-60 CTR cells was determined by flow cytometric analysis. Cells were resuspended into $5 \times 10^{5}$ cells $/ \mathrm{ml}$ and were collected for 
nuclear staining which was performed according to the manufacturer's instructions using Flow Cytometry Analysis of Cell Cycle Kit (GENMED, Shanghai). Following staining, cells were immediately analyzed by flow cytometry.

\section{Nuclear and Cytoplasmic Proteins Extraction}

The nuclear and cytoplasmic proteins were extracted using an Nuclear and Cytoplasmic Protein Extraction Kit (Keygen, Shanghai, China) according to the manufacturer's instructions. Cells were harvest and washed with icecold PBS. Supernatant was carefully remove and discard. The cells were mixed with Buffer A and Buffer B and the tube was incubated on ice for $30 \mathrm{~min}$. Vortex the tube at $3000 \times g$ for $10 \mathrm{~min}$ to fully suspend the cell pellet. Immediately transfer the supernatant (cytoplasmic extract) to a clean pre-chilled tube. Suspend the insoluble fraction in Buffer C. Vortex on the highest setting for $15 \mathrm{~s}$. Place the sample on ice for $30 \mathrm{~min}$ and continue vortexing for $15 \mathrm{~s}$ every $10 \mathrm{~min}$, for a total of $40 \mathrm{~min}$. Centrifuge the tube at $14,000 \times \mathrm{g}$ in a microcentrifuge for $30 \mathrm{~min}$. Immediately transfer the supernatant (nuclear extract) fraction to a clean pre-chilled tube. Store extracts at $-80^{\circ} \mathrm{C}$ until use. The protein concentrations were determined using a BCA protein assay according to the manufacturer's instructions.

\section{Western blotting}

Expressions of SATB1 were detected in HL-60, NB4, HEL and THP-1 cells and compared in HL-60 SATB1shRNA1 cells, HL-60 SATB1-shRNA2 cells and HL-60 CTR cells using western blotting. Expressions of p38 MAPK, phospho-p38 MAPK, Akt, phospho-Akt, total

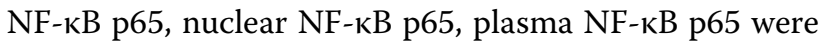
also analyzed in HL-60 SATB1-shRNA cells and HL-60 CTR cells using western blotting according to the standard procedure [28]. Rabbit anti-SATB1 primary antibodies (1:3500 dilution) and horseradish-peroxidase conjugated anti-rabbit IgG secondary antibody (1:3000 dilution) were used.

\section{Gene expression profiling and the KEGG pathway analysis}

Integrity of total RNA was checked using the Agilent 2100 Bio-analyzer (Agilent, Santa Clara, USA). Gene expression profiling was performed by the Dana-Farber Microarray Core Facility using Affymetrix U133 Plus 2.0 chip (Affymetrix, Santa Clara, USA) following the manufacturer's guidelines, and data was analyzed by DAVID software. Gene expression was compared between HL-60 SATB1-shRNA1 cells and HL-60 CTR cells and analyzed by KEGG Pathway. Genes that displayed two-fold upregulation or 0.5 -fold down-regulation in expression in comparisons were selected for further analyses. Arrays with poor quality according to the manufacturer's recommendations were excluded from further analysis.

\section{Statistical analysis}

The data were reported as mean \pm S.D. Differences among three groups were determined by analysis of Mann-Whitney $U$, whereas differences between two groups were evaluated by the Student's $t$ test. Chi square test was done to study the association of SATB1 expression with multiple factors. $P$ values less than 0.05 were considered statistically significant. Statistical analysis was performed by the SPSS 19.0 (SPSS Inc., Chicago, USA) statistical software programs.

\section{Results \\ SATB1 expression was decreased in AML patients}

To evaluate the association between SATB1 and AML, SATB1 expression was detected in 52 newly diagnosed AML patients and the normal control. Results showed that $S A T B 1$ mRNA expression was significantly lower in AML samples $(P<0.0001$, Fig. 1a). In 52 newly diagnosed AML patients, 29 patients received CR after one or two cycles of chemotherapy. We then evaluated the correlations between SATB1 and AML status. SATB1 expression was increased in $C R$ patients compared to their initial samples $(P=0.0306$, Fig. 1b), indicating that SATB1 could be a predictor for better response to treatment. According to the average expression of SATB1 of $52 \mathrm{AML}$ patients, patients were then categorized into $S A T B 1_{\text {high }}$ and $S A T B 1_{\text {low }}$, of which the CR rate was $76.47 \%$ and $56.14 \%$, respectively $(P=0.1891$, Table 1$)$. Next, we analyzed the correlation between SATB1 expression and FAB category to assess whether low SATB1 expression is indicated in some specific subtypes of AML with poor clinical outcome. We observed no difference among FAB subtypes of AML regarding SATB1 expression which also has not been related to age, sex, blood cell count and percentage of blast (Fig. 1c).

\footnotetext{
(See figure on next page.)

Fig. 1 SATB1 expression was decreased both in newly diagnosed AML patients and AML cell lines compared to healthy donors, but increased after patients achieved CR. a SATB1 mRNA expression was lower in 52 newly diagnosed AML patients compared to 38 healthy donors $(P<0.0001)$. b SATB1 mRNA expression was increased in 29 CR samples compared to their initial AML samples $(P=0.0306)$. c SATB1 expression in AML based on FAB classification including 3 cases of mixed AML. d SATB1 mRNA expression was lower in 4 AML cell lines: HL-60, NB4, HEL and THP-1 (P<0.0001). e, f Western blotting showed that SATB1 exhibited highest expression in HL-60 cells among 4 AML cell lines $(P<0.0001)$
} 


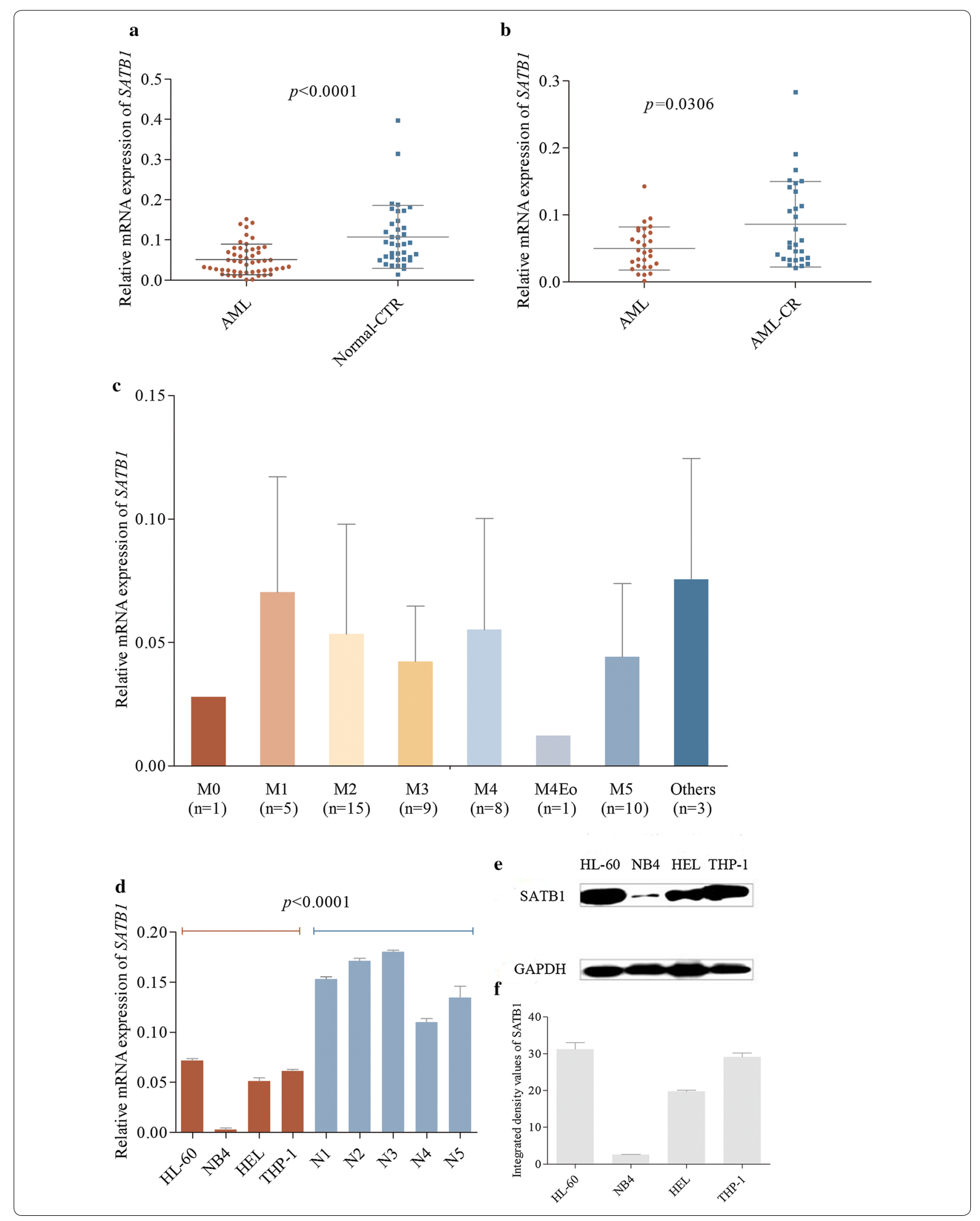




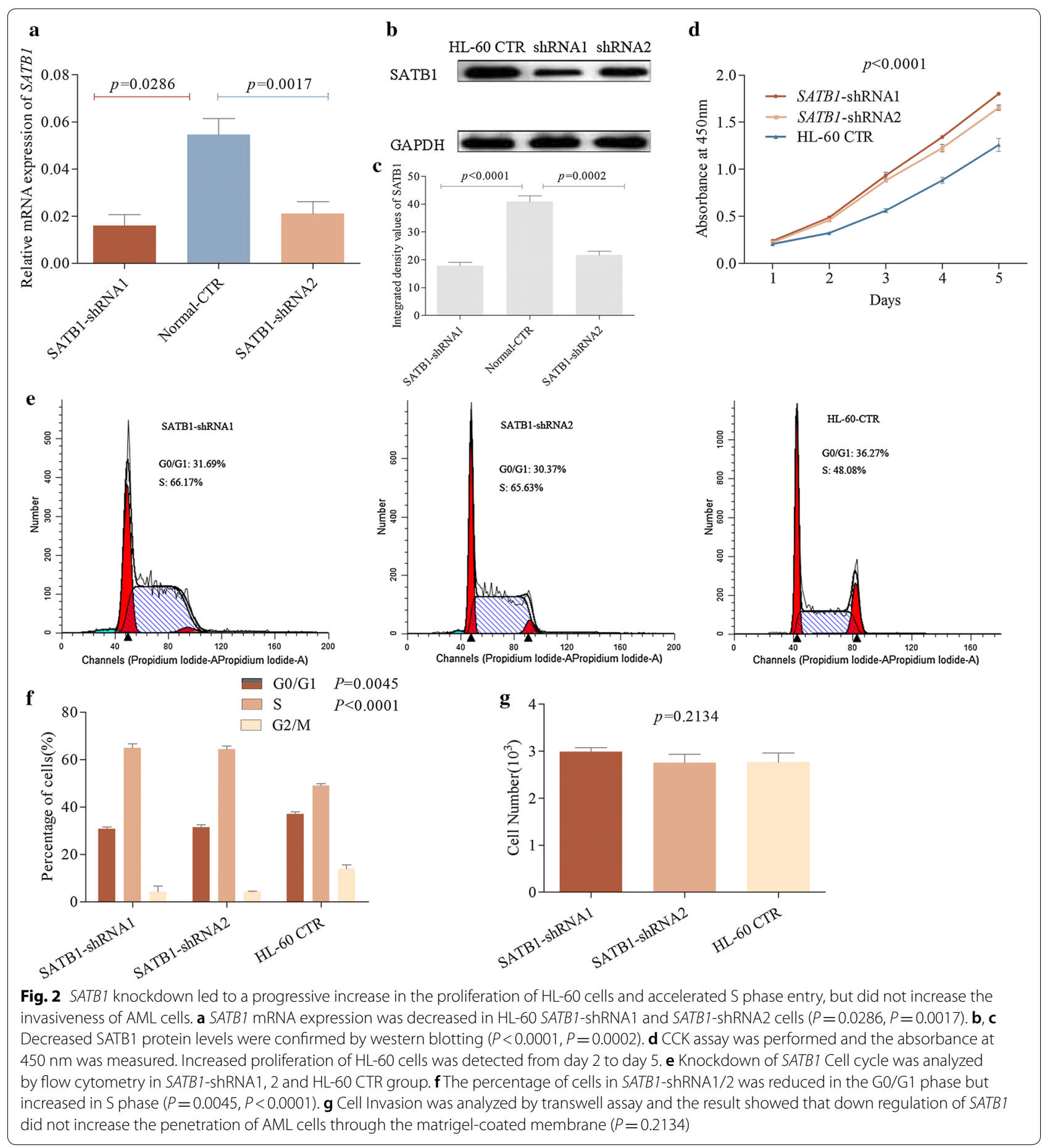

\section{Knockdown of SATB1 enhanced the proliferation of AML cells}

To define the association between SATB1 expression and the development of AML, we evaluated SATB1 expression in HL-60, NB4, HEL, THP-1 cells and samples from healthy donors as control. Results showed that SATB1 expression was decreased in all AML cell lines than in control $(P<0.0001$, Fig. 1d). SATB1 exhibited highest expression in HL-60 cells among 4 different cell lines $(P<0.0001$, Fig. 1e, $\mathrm{f})$, we investigated its role in HL-60 by shRNAs mediated knockdown of $S A T B 1$. As shown in Fig. 2a, b, C HL-60 SATB1-shRNA1 and SATB1-shRNA2 cells exhibited decreased SATB1 expression compared to the control (HL-60-CTR) both in the mRNA $(P=0.0286$, 


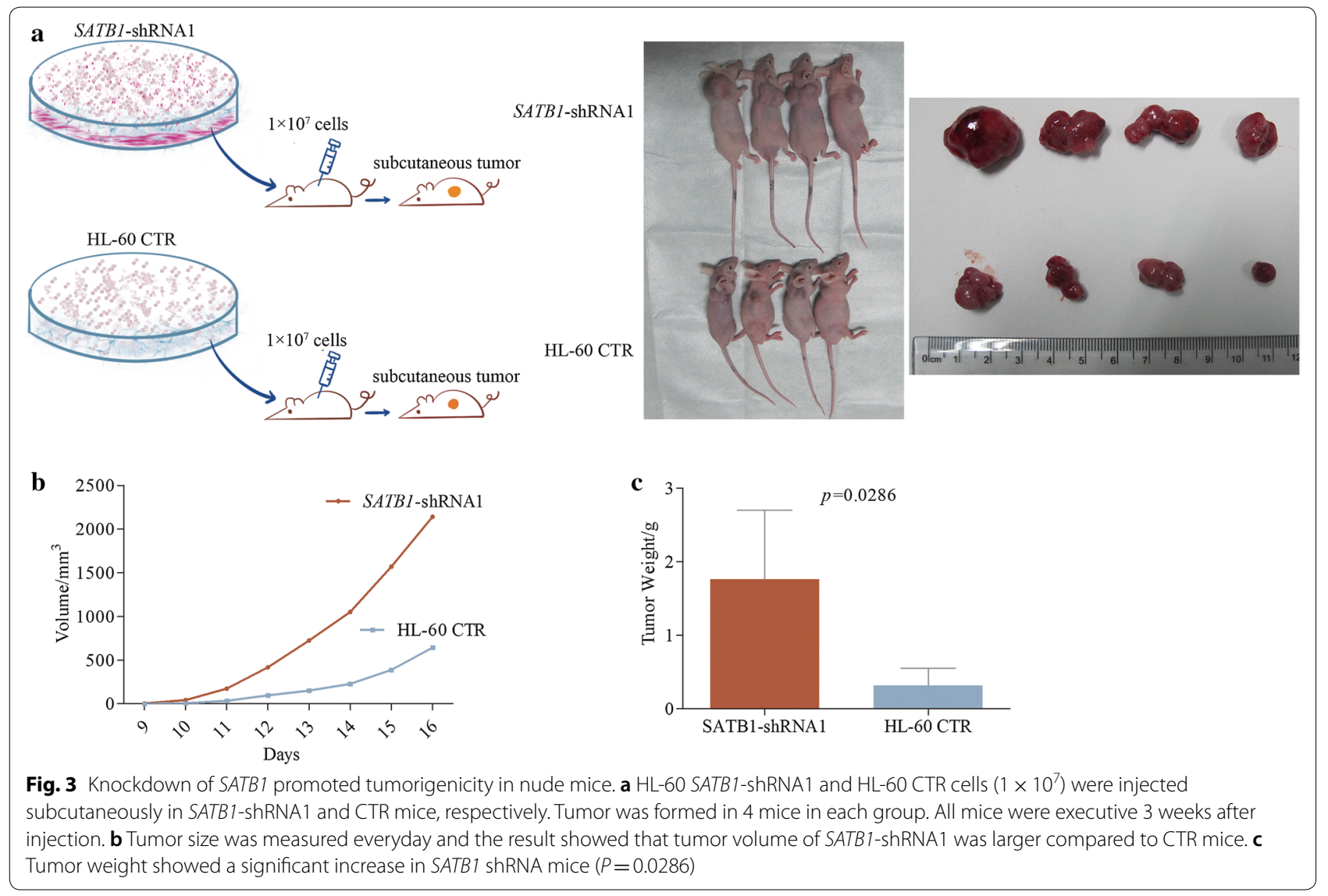

$P=0.0017)$ and protein levels $(P<0.0001, P=0.0002)$, suggesting that the stable $S A T B 1$ knockdown cells were successfully established. To define the role of SATB1 in HL-60 cells, we performed CCK8 assay to evaluate the proliferation of HL-60 SATB1-shRNA cells. SATB1 knockdown led to a progressive increase in the proliferation of HL-60 cells both in SATB1-shRNA1 and SATB1shRNA2 groups since day $2(P<0.0001$, Fig. $2 d)$.

\section{Down regulation of SATB1 accelerated S phase entry but did not increase the invasiveness of AML cells}

To study the effect of SATB1 on AML cell cycle, we compared the number of quiescent and actively cycling HL-60 cells in SATB1 shRNA1, SATB1 shRNA2 and CTR group using flow cytometry. The number of quiescent cells in the G0/G1 phase of the cell cycle was significantly reduced in the absence of SATB1 $(P=0.0045)$. Consistently, the number of cells in $S$ phase was increased $(P<0.0001)$, which suggested that SATB1 promoted quiescence of AML cells while knockdown of SATB1 enhanced cell activation (Fig. 2e, f). In order to further evaluate the impact of SATB1 on the invasiveness of AML cells, we cultured HL-60-CTR cells and HL-60 SATB1-shRNA cells in transwell matrigel-coated chambers under the same conditions and compare the invasiveness between both cell lines. We found that shRNA mediated knockdown of SATB1 did not cause significant increase of penetration through the matrigelcoated membrane, which showed similar invasiveness as HL-60-CTR cells (Fig. 2g, $P=0.2134$ ).

\section{Knockdown of SATB1 promoted tumorigenicity in nude mice}

To further test if SATB1 knockdown could promote AML progression in vivo, we compared the tumor size and weight in HL-60 SATB1-shRNA1 cells treated mice and the CTR mice. Mice were injected subcutaneously with $1 \times 10^{7}$ HL-60 SATB1-shRNA1 cells $\left.(\mathrm{N}=6)\right)$ or HL-60 cells $(\mathrm{CTR}, \mathrm{N}=6)$ and all mice were executive 3 weeks after injection (Fig. 3a). Tumor was formed in 4 SATB1shRNA1 mice and 4 CTR mice at the average time of $9 \pm 1$ day and $10 \pm 1$ day, respectively. Tumor size was compared from day 9 to day 16 and SATB1 shRNA mice showed a larger tumor volume compared to CTR mice (Fig. 3b). At the end of the experiment, tumor weight was measured and showed a significant increase in SATB1 shRNA mice compared to CTR mice ( $P=0.0286$, Fig. 3c). 


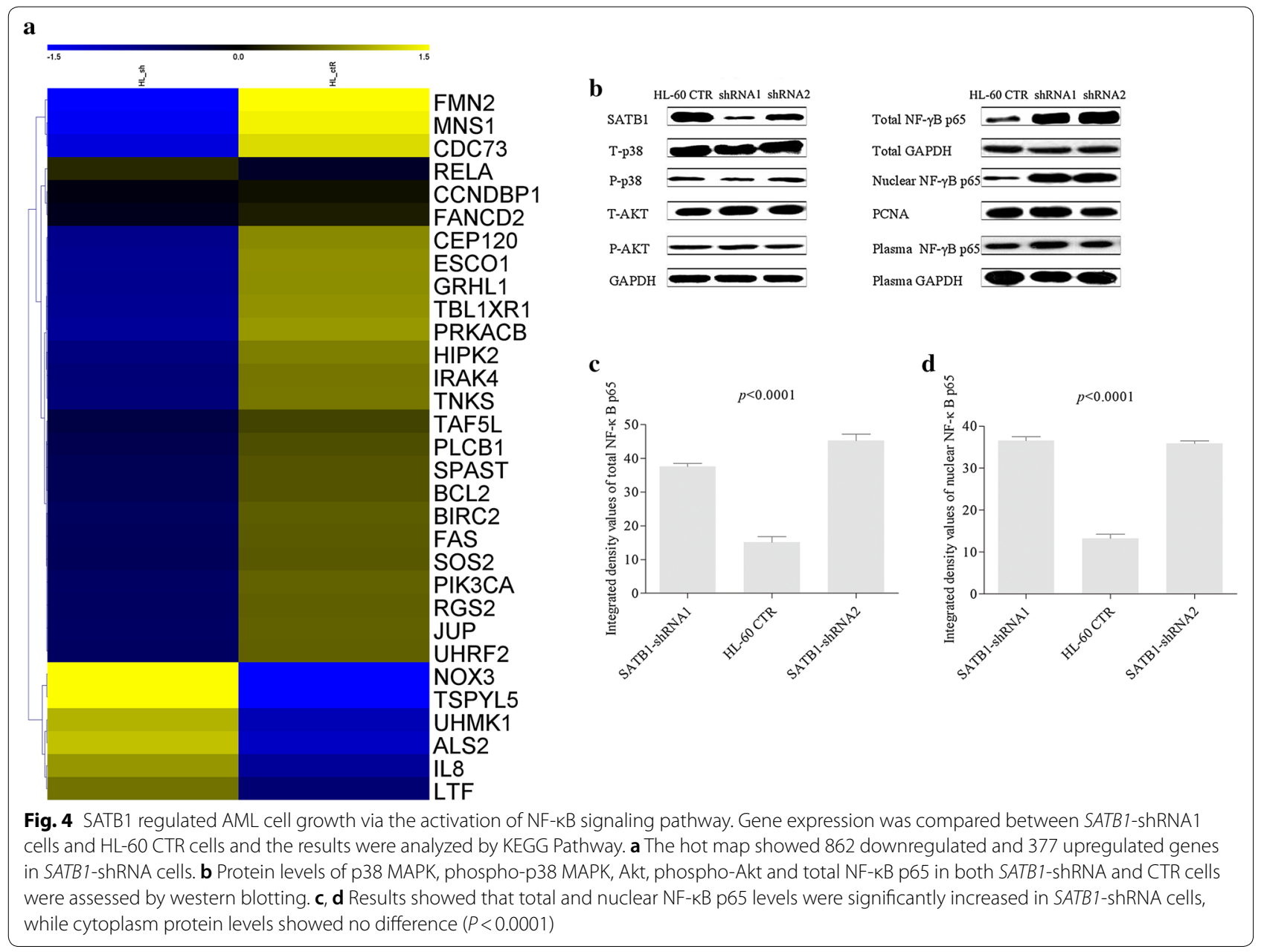

\section{SATB1 regulated AML cell growth via the activation of NF-KB signaling pathway}

To investigate the mechanisms underlying the enhanced proliferation of HL-60 SATB1-shRNA cells, we analyzed the global gene expression profiles of HL-60 SATB1shRNA cells and HL-60-CTR cells. Genes were identified as differentially expressed if their expression showed at least two-fold difference in each of the comparisons. Using these criteria, we identified 862 downregulated and 377 upregulated genes in HL-60 SATB1-shRNA cells (Fig. 4a). Downregulated genes were involved in the regulation of cell cycle, proliferation, apoptosis and cell death. Upregulated genes were involved in chromatin assembly and disassembly, protein-DNA complexes assembly, cellular cation homeostasis and inflammatory response. KEGG based analysis was used to determine whether particular biological pathways gene expression was more highly represented in HL-60 SATB1-shRNA cells versus HL-60-CTR cells. Differentially expressed genes were involved in NF-kB, MAPK and PI3 K/Akt signaling pathways. We therefore assessed the protein levels of p38 MAPK, phospho-p38 MAPK, Akt, phospho-Akt and total NF-kB p65 in both SATB1-shRNA and CTR cells. Results showed that total NF- $\mathrm{kB}$ p65 levels were significantly increased in HL-60 SATB1-shRNA cells (Fig. 4b, c). Since nuclear and cytoplasm NF-кB p65 play different roles in cell proliferation, we next compared both nuclear and cytoplasm NF-kB p65 levels among groups. Nuclear NF-kB p65 levels were significantly increased in HL-60 SATB1-shRNA cells, while cytoplasm protein levels showed no difference (Fig. 4d). Together, these results indicate that shRNA mediated knockdown of SATB1 regulated AML cell growth via the activation of NF- $\mathrm{kB}$ signaling pathway.

\section{Discussions}

SATB1 is a global genomic organizer that participates in activation and inactivation of genes and the differentiation of embryonic stem cells, thus is implicated in a variety of cancers and cancer progression $[4,5,15$, 17, 22, 29-31]. Up-regulation of SATB1 was found in many epithelial tumors and negatively correlated with 
the prognostic properties and clinical outcome $[6,15$, 32]. Recent studies in cells with SATB1 knockdown have emphasized the functional relevance of SATB1 to carcinogenesis $[17,32,33]$. The mechanism by which SATB1 regulate cancer development remains unclear and has been extensively studied. It's reported that SATB1 might cooperatively regulate expression of the anti-apoptotic BCL2 and pro-apoptotic NOXA genes to participate in disruption of apoptosis, which is a hallmark of cancer that reinforces tumorigenesis and resistance to cytotoxic cancer therapies [6, 34]. However, SATB1 expression was decreased rather than increased in hematology malignancy. We previously reported that SATB1 expressions were up-regulated in T-ALL. Knockdown of SATB1 have enhanced invasive potential in Jurkat cells [24]. These observations raised interesting questions of whether SATB1 play the similar role in AML as in T-ALL or in epithelial tumors and whether it could be one of the potential treatment targets for AML. In this study, our data showed that SATB1 expression was deregulated in 52 initial AML samples, which is in line with our own findings on T-ALL. By comparing SATB1 expression of pair initial AML and CR patients, we found that SATB1 expression was increased in CR patients. Although the $\mathrm{CR}$ rate was not significantly increased as expected as SATB1 expression was up-regulated, it's higher in SATB$1_{\text {high }}$ patients and the difference could be statistical significant if the sample size is larger. We then confirmed decreased SATB1 expression in different AML cell lines and found that SATB1 was more specific in HL-60 cells. These data suggested that down-regulation of SATB1 could be an important factor in leukemogenesis.

SATB1 is predominantly expressed in the thymus and highly associated with thymocyte differentiation. It is thought to induce lymphopoiesis and regulate the expression of various genes during lymphocyte especially $\mathrm{T}$ cell development, so SATB1 is thought to be correlated to the development of ALL [18-22, 28, 31, 35-40]. SATB1 regulates many genes involved in HSC lineage decisions and development, but evidence that supports the role of SATB1 in AML remained elusive [41, 42]. It is reported that SATB1-deficient HSCs were found to be less quiescent and more prone to differentiate to myeloid-erythroid lineages, which indicated that SATB1 is associated with the regulation of myeloid lineages and its dysfunction could be linked to AML $[1-6,25,29]$.

One aim of this study was to describe the association between SATB1 and AML. SATB1 was knockdown in the selected HL-60 cell line. We observed that knockdown of $S A T B 1$ resulted in a progressive proliferation of HL-60 cells. HL-60 SATB1-shRNA cells were then injected subcutaneously in mice. As expected, progression of leukemia was proved by significant increased tumor weight, suggesting that SATB1 knockdown could increase AML proliferation both in vitro and in vivo. In addition, cell cycle analysis was then performed and we showed that down regulation of $S A T B 1$ could promote cell activation by accelerating $S$ phase entry. These results suggest an indispensable role of SATB1 in the development of AML. However, we did not observe a significant increased in the invasiveness of AML cells after knockdown of SATB1. It is difficult to make a conclusion that SATB1 is dispensable for the invasiveness of AML because AML arise as a consequence of a number of genetic aberrations and multiple molecular events; the invasiveness of different subtypes of AML varied and results from only one AML cell line can not tell the whole story. More detailed analysis is necessary for the mechanisms underlying the enhanced proliferation of AML cells by SATB1.

SATB1 regulates multiple genes in lymphocyte differentiation. It is reported that SATB1 interacted with $\beta$-catenin which acts as a transcriptional regulator mediating Wnt signaling thus inducing target gene expressions [24, 36, 43]. SATB1 also associate with epigenetic modifiers such as histone deacetylase which is important for lymphocyte development [20]. However, what target genes and the associated signal pathways are possibly involved in the regulation of AML by SATB1has not been clarified. In this study, we compared the global gene expression profiles of HL-60 SATB1-shRNA cells and HL-60-CTR cells. For those differentially expressed genes which were involved in NF- $\mathrm{KB}$, MAPK and PI3K/Akt signaling pathways, we assessed the protein levels and found that nuclear NF- $\mathrm{kB}$ p65 levels were significantly increased in HL-60 SATB1-shRNA cells, while cytoplasm protein levels showed no difference when compared to HL-60-CTR cells. These findings suggested that knockdown of SATB1 might regulate AML cell growth via the activation of NF- $\mathrm{kB}$ signaling pathway.

\section{Conclusions}

We demonstrated in this study that impairment of SATB1 is associated with AML. Knockdown of SATB1 promoted cell proliferation and tumorigenicity of AML via the activation of NF- $\kappa B$ signaling pathway. Further study about gene regulatory network modulated by SATB1 may lead to the development of a new treatment of AML.

\section{Abbreviations}

SATB1: special AT-rich sequence-binding protein 1; AML: acute myeloid leukemia; HSCT: hematopoietic stem cell transplantation; T-ALL: T cell leukemia/ lymphoma; CR: complete remission; CCK8: Cell Counting Kit-8.

\section{Acknowledgements}

The authors would like to thank Prof. Yangqiu Li from Jinan University, China for technical support and writing assistance. 


\section{Authors' contributions}

XL has made substantial contributions to conception and design, and has been involved in drafting and revising the manuscript. LX has contributed to formal analysis, and data analysis. XW has contributed to formal analysis and animal experiments. HT has revised the manuscript and LL has contributed to the data analysis and animal experiments. All authors read and approved the final manuscript.

\section{Funding}

This work is supported by grant from National Natural Science Foundation of China $(81870113,81672661)$ and Guangdong Province Natural Science Foundation (2016A030313598, 2018A030313661), and Guangzhou Science and Technology Project (201804010199).

\section{Availability of data and materials}

The datasets used and/or analyzed during the current study are available from the corresponding author upon reasonable request.

\section{Ethics approval and consent to participate}

Informed consent was obtained from all patients and ethics approval was obtained from Committee on the Ethics of the First Affiliated Hospital of Guangzhou Medical University (Permit number: 2012-41). The animal experiments were carried out in strict accordance with the recommendations in the Guide for the Care and Use of Laboratory Animals of Guangzhou Medical University. Animals were purchased from Animal experimental center, Guangdong, China. The protocol was approved by the Committee on the Ethics of the First Affiliated Hospital of Guangzhou Medical University (Permit number: SYXK 2016-0168). All surgery was performed under sodium pentobarbital anesthesia, and all efforts were made to minimize suffering.

\section{Consent for publication}

Not applicable.

\section{Competing interests}

The authors declare that they have no competing interests.

Received: 11 February 2019 Accepted: 7 May 2019

Published online: 17 May 2019

\section{References}

1. Watts J, Nimer S. Recent advances in the understanding and treatment of acute myeloid leukemia. F1000Res. 2018;(7):1-14.

2. Bose P, Vachhani P, Cortes JE. Treatment of relapsed/refractory acute myeloid leukemia. Curr Treat Options Oncol. 2017;18(3):17.

3. Bachas C, Schuurhuis GJ, Zwaan CM, van den Heuvel-Eibrink MM, den Boer ML, de Bont ES, et al. Gene expression profiles associated with pediatric relapsed AML. PLoS ONE. 2015;10(4):e0121730.

4. Torkildsen S, Brunetti M, Gorunova L, Spetalen S, Beiske K, Heim S, et al. Rearrangement of the chromatin organizer special AT-rich binding protein 1 gene, SATB1, resulting from at $(3 ; 5)(p 24 ; q 14)$ chromosomal translocation in acute myeloid leukemia. Anticancer Res. 2017;37(2):693-8.

5. Mesuraca M, Amodio N, Chiarella E, Scicchitano S, Aloisio A, Codispoti $B$, et al. Turning stem cells bad: generation of clinically relevant models of human acute myeloid leukemia through gene delivery- or genome editing-based approaches. Molecules. 2018;23(8):2060.

6. Yang Y, Wang Z, Sun L, Shao L, Yang N, Yu D, et al. SATB1 mediates longrange chromatin interactions: a dual regulator of anti-apoptotic BCL2 and pro-apoptotic NOXA genes. PLoS ONE. 2015;10(9):e0139170.

7. Stavast CJ, Leenen PJM, Erkeland SJ. The interplay between critical transcription factors and microRNAs in the control of normal and malignant myelopoiesis. Cancer Lett. 2018;427:28-37.

8. Cao XX, Cai H, Mao YY, Wu Q, Zhang L, Zhou DB, et al. Next-generation sequencing-based genetic landscape and its clinical implications for Chinese acute myeloid leukemia patients. Cancer Cell Int. 2018;18:215.

9. Zhang Y, LiY.T cell receptor-engineered T cells for leukemia immunotherapy. Cancer Cell Int. 2019;19:2.

10. Mansour MA, Hyodo T, Akter KA, Kokuryo T, Uehara K, Nagino M, et al. SATB1 and SATB2 play opposing roles in c-Myc expression and progression of colorectal cancer. Oncotarget. 2016;7(4):4993-5006.
11. Wang S, Zeng J, Xiao R, Xu G, Liu G, Xiong D, et al. Poor prognosis and SATB1 overexpression in solid tumors: a meta-analysis. Cancer Manage Res. 2018;10:1471-8.

12. Cai S, Lee CC, Kohwi-Shigematsu T. SATB1 packages densely looped, transcriptionally active chromatin for coordinated expression of cytokine genes. Nat Genet. 2006;38(11):1278-88.

13. Han HJ, Russo J, Kohwi Y, Kohwi-Shigematsu T. SATB1 reprogrammes gene expression to promote breast tumour growth and metastasis. Nature. 2008;452(7184):187-93.

14. Sun F, Lu X, Li H, Peng Z, Wu K, Wang G, et al. Special AT-rich sequence binding protein 1 regulates the multidrug resistance and invasion of human gastric cancer cells. Oncol Lett. 2012;4(1):156-62.

15. Naik R, Galande S. SATB family chromatin organizers as master regulators of tumor progression. Oncogene. 2018;9:1989-2004.

16. Zhai S, Xue J, Wang Z, Hu L. High expression of special AT-rich sequence binding protein-1 predicts esophageal squamous cell carcinoma relapse and poor prognosis. Oncol Lett. 2017;14(6):7455-60.

17. Fromberg A, Engeland $K$, Aigner A. The special AT-rich sequence binding protein 1 (SATB1) and its role in solid tumors. Cancer Lett. 2018:417:96-111.

18. Beyer M, Thabet Y, Muller RU, Sadlon T, Classen S, Lahl K, et al. Repression of the genome organizer SATB1 in regulatory T cells is required for suppressive function and inhibition of effector differentiation. Nat Immunol. 2011;12(9):898-907.

19. Kakugawa K, Kojo S, Tanaka H, Seo W, Endo TA, Kitagawa Y, et al. Essential roles of SATB1 in specifying T lymphocyte subsets. Cell Rep. 2017;19(6):1176-88

20. Stephen TL, Payne KK, Chaurio RA, Allegrezza MJ, Zhu H, Perez-Sanz J, et al. SATB1 expression governs epigenetic repression of PD-1 in tumorreactive T cells. Immunity. 2017;46(1):51-64.

21. Poglio S, Merlio JP. SATB1 is a pivotal epigenetic biomarker in cutaneous T-cell lymphomas. J Invest Dermatol. 2018;138(8):1694-6.

22. Fredholm S, Willerslev-Olsen A, Met O, Kubat L, Gluud M, Mathiasen SL, et al. SATB1 in malignant T cells. J Invest Dermatol. 2018;138(8):1805-15.

23. Liu J, Li Y, Lu Z, Gu J, Liang Y, Huang E, et al. Deceleration of glycometabolism impedes IgG-producing B-cell-mediated tumor elimination by targeting SATB1. Immunology. 2019;156(1):56-68.

24. Luo XD, Yang SJ, Wang JN, Tan L, Liu D, Wang YY, et al. Downregulation of SATB1 increases the invasiveness of Jurkat cell via activation of the WNT/ beta-catenin signaling pathway in vitro. Tumour Biol. 2016;37(6):7413-9.

25. Steidl U, Steidl C, Ebralidze A, Chapuy B, Han HJ, Will B, et al. A distal single nucleotide polymorphism alters long-range regulation of the PU.1 gene in acute myeloid leukemia. J Clin Invest. 2007;117(9):2611-20.

26. Salom F, Piedra W, Burgos H. Tumor growth rate of pancreatic serous cystadenomas: endosonographic follow-up with volume measurement to predict cyst enlargement. Pancreatology. 2019;19(1):122-6.

27. Stepanenko AA, Andreieva SV, Korets KV, Mykytenko DO, Baklaushev VP, Huleyuk NL, et al. Temozolomide promotes genomic and phenotypic changes in glioblastoma cells. Cancer Cell Int. 2016;16:36.

28. Nie H, Maika SD, Tucker PW, Gottlieb PD. A role for SATB1, a nuclear matrix association region-binding protein, in the development of CD8SP thymocytes and peripheral T lymphocytes. J Immunol. 2005;174(8):4745-52.

29. Will B, Vogler TO, Bartholdy B, Garrett-Bakelman F, Mayer J, Barreyro L, et al. Satb1 regulates the self-renewal of hematopoietic stem cells by promoting quiescence and repressing differentiation commitment. Nat Immunol. 2013;14(5):437-45.

30. Borghesi L. Hematopoiesis in steady-state versus stress: self-renewal, lineage fate choice, and the conversion of danger signals into cytokine signals in hematopoietic stem cells. J Immunol. 2014;193(5):2053-8.

31. Goolam M, Zernicka-Goetz M. The chromatin modifier Satb1 regulates cell fate through Fgf signalling in the early mouse embryo. Development. 2017;144(8):1450-61.

32. Yasui D, Miyano M, Cai S, Varga-Weisz P, Kohwi-Shigematsu T. SATB1 targets chromatin remodelling to regulate genes over long distances. Nature. 2002;419(6907):641-5.

33. Sunkara KP, Gupta G, Hansbro PM, Dua K, Bebawy M. Functional relevance of SATB1 in immune regulation and tumorigenesis. Biomed Pharmacother. 2018;104:87-93.

34. Ramakrishnan M, Liu WM, DiCroce PA, Posner A, Zheng J, Kohwi-Shigematsu T, et al. Modulated binding of SATB1, a matrix attachment region 
protein, to the AT-rich sequence flanking the major breakpoint region of BCL2. Mol Cell Biol. 2000;20(3):868-77.

35. Ahlfors H, Limaye A, Elo LL, Tuomela S, Burute M, Gottimukkala KV, et al. SATB1 dictates expression of multiple genes including IL-5 involved in human T helper cell differentiation. Blood. 2010;116(9):1443-53.

36. Notani D, Gottimukkala KP, Jayani RS, Limaye AS, Damle MV, Mehta S, et al. Global regulator SATB1 recruits beta-catenin and regulates $T(\mathrm{H}) 2$ differentiation in Wnt-dependent manner. PLoS Biol. 2010;8(1):e1000296.

37. Burute M, Gottimukkala K, Galande S. Chromatin organizer SATB1 is an important determinant of T-cell differentiation. Immunol Cell Biol. 2012;90(9):852-9.

38. Grzanka J, Leveson-Gower D, Golab K, Wang XJ, Marek-Trzonkowska N Krzystyniak A, et al. FoxP3, Helios, and SATB1: roles and relationships in regulatory T cells. Int Immunopharmacol. 2013;16(3):343-7.

39. Gottimukkala KP, Jangid R, Patta I, Sultana DA, Sharma A, Misra-Sen J, et al. Regulation of SATB1 during thymocyte development by TCR signaling. Mol Immunol. 2016;77:34-43.

40. Chorro L, Suzuki M, Chin SS, Williams TM, Snapp EL, Odagiu L, et al. Interleukin 2 modulates thymic-derived regulatory $T$ cell epigenetic landscape. Nat Commun. 2018:9(1):5368.
41. Doi Y, Yokota T, Satoh Y, Okuzaki D, Tokunaga M, Ishibashi T, et al. SATB1 levels regulate hematopoietic stem cell heterogeneity with distinct lineage fate. Cell Rep. 2018;23(11):3223-35.

42. Carrelha J, Meng Y, Kettyle LM, Luis TC, Norfo R, Alcolea V, et al. Hierarchically related lineage-restricted fates of multipotent haematopoietic stem cells. Nature. 2018;554(7690):106-11.

43. Li Q, Dashwood WM, Zhong X, Nakagama H, Dashwood RH. Bcl-2 overexpression in PhIP-induced colon tumors: cloning of the rat $\mathrm{BCl}-2$ promoter and characterization of a pathway involving beta-catenin, c-Myc and E2F1. Oncogene. 2007;26(42):6194-202.

\section{Publisher's Note}

Springer Nature remains neutral with regard to jurisdictional claims in published maps and institutional affiliations.
Ready to submit your research? Choose BMC and benefit from:

- fast, convenient online submission

- thorough peer review by experienced researchers in your field

- rapid publication on acceptance

- support for research data, including large and complex data types

- gold Open Access which fosters wider collaboration and increased citations

- maximum visibility for your research: over $100 \mathrm{M}$ website views per year

At BMC, research is always in progress.

Learn more biomedcentral.com/submissions 